\title{
Electromechanical Modeling and Simulation of Piezoelectric Vibration based Energy Harvester Interfaced with MPPT based Electrical Circuit Using Matlab Simulink
}

\author{
Priti Yadav, Manisha, Prerna Gaur
}

\begin{abstract}
Wind vibration based energy harvester using piezoelectric material has been of great concern to researchers for a long time for low power generation and applications. In this paper, wind generated vibrations are used to develop electromechanical model of piezoelectric vibration energy harvester to generate electrical output using MATLAB simulink and comparision has been drawn between an electromechanical model of piezoelectric harvester interfaced with $P \& O$ MPPT based electrical model and without it. It has been found that overall model with MPPT provides high output with high efficiency.
\end{abstract}

Keywords--- Piezoelectric, Harvester, Vibration, MPPT

\section{INTRODUCTION}

The vibrations created by wind in wind power generation, can be used as source for electrical power generation and application. As piezoelectric material provides better response to vibrations, to use it as an energy harvester its electromechanical simulink model using MATLAB have been used. The electromechanical equivalent model of piezoelectric harvester takes vibrational force as input to generate the sinusoidally varying AC electrical output which needs to be rectified for making it available for power applications and hence the piezoelectric model is then interfaced with the electrical circuit comprised of a PWM single phase full wave rectifier which generates pulsating dc output, this needs to be converted into constant dc output of appropriate voltage level, so a P\&O MPPT controlled DCDC type Boost converter is uesd where MPPT is used to provide controlled duty cycle to the switch of boost converter so that we can achieve the desired electrical output.

The theoretical modeling of piezoelectric vibration energy harvester and the interfaced electrical circuit have been discussed here.

\section{Modelling of Electromechanical equivalent piezoelectric} vibrational energy harvester

A Second order mass-spring damper is used to model the piezoelectric vibration energy harvester [1,2]. The harvester frame consists of a suspended mass ' $M$ ' on a spring of stiffness constant Ks and a damper of coefficient D which represents mechanical damping due to wind vibrations, air friction etc. The external force will cause the movement in

Manuscript received September 16, 2019.

Priti Yadav, NSIT. (e-mail: pritiyadav101@ gmail.com)

Manisha, Assistant Professor, NSUT (Formerly NSIT).

(e-mail: manisha.singh@nsut.ac.in)

Prerna Gaur, Professor, NSUT (Formerly NSIT).

(e-mail: prernagaur@yahoo) mass which will cause deformation of the connected piezo element. As piezoelectric transducer works on the principle of piezoelectric effect, applied mechanical

stress on the piezoelectric material will produce electric voltage. It is considered that external vibrational force acting is sinusoidal in nature, due to this sinusoidal vibrational force frame moves harmonically which is given

by $[7,8]$

External force applied on frame due to wind speed in wind turbine is given as

$$
F=\frac{T}{r \sin \theta}
$$

where, $\mathrm{T}$ is Torque developed in wind turbine $r$ is the distance from axis of rotation

$\theta$ is the angle between $\mathrm{F}$ and $\mathrm{r}$

Since the external force is sinusoidal in nature it is given as

$$
f(t)=F_{m} \sin (w t+\phi)(2)
$$

$\mathrm{F}_{\mathrm{m}}$ is amplitude of frame motion

$\mathrm{w}$ is angular vibrational frequency

Relative motion of mass with respect to frame is given by

$$
r(t)=R_{m} \sin (w t+\phi)(3)
$$

$R_{m}$ is amplitude of mass motion

$\phi$ is phase difference between $\mathrm{f}(\mathrm{t})$ and $\mathrm{r}(\mathrm{t})$

The dynamic equation as per D'Almbert's law for the above system and taking laplace transform we get

$$
\frac{R(s)}{F(s)}=\frac{M s^{2}}{M s^{2}+D s+K}
$$

where, the natural frequency is given as $\mathrm{w}_{\mathrm{n}}=\sqrt{\frac{K}{M}}$ and damping term is given as $\xi=\frac{D}{2} \sqrt{\frac{M}{K}}$

\section{Modeling of Interfaced Electrical circuit}

The sinusoidal voltage generated by piezoelectric vibrational energy harvester is then given to the single phase full wave PWM rectifier to produce the pulsating full wave dc output, PWM rectifier is used to reduce the harmonic distortion created by switches in the rectifier circuit. The DC output from single phase full wave rectifier is given as

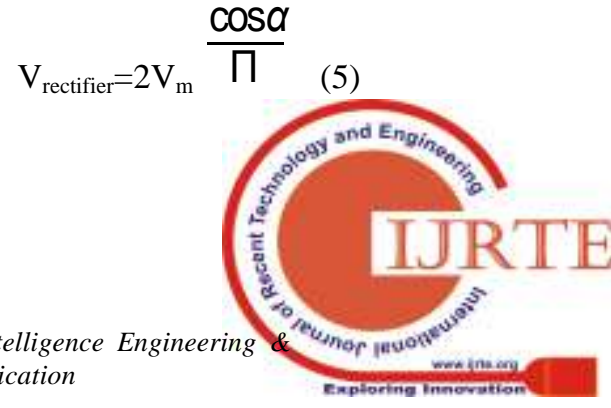




\section{ELECTROMECHANICAL MODELING AND SIMULATION OF PIEZOELECTRIC VIBRATION BASED ENERGY HARVESTER INTERFACED WITH MPPT BASED ELECTRICAL CIRCUIT USING MATLAB SIMULINK}

where, $\mathrm{V}_{\text {rectifier }}$ is DC output from the rectifier, $\mathrm{V}_{\mathrm{m}}$ is the maximum value of input ac voltage from the piezoelectric material, $\alpha$ is the duty ratio.

After the rectifier, a P\&O MPPT is used to generate the duty cycle for the switch of DC-DC boost converter, $\mathrm{P} \& \mathrm{O}$ MPPT takes the voltage and current from rectifier output as input and produces duty cycle using PWM method as per the reference signal provided. The duty cycle generated by the MPPT is then given to the switch of boost converter to raise the voltage level for making it appropriate for various applications.

$$
\mathrm{V}_{\text {boost }}=\frac{D}{1-D} \mathrm{~V}_{\text {rectifier }}(6)
$$

where $\mathrm{V}_{\text {boost }}$ is the output dc voltage from boost converter as per the given input $\mathrm{V}_{\text {rectifier, }} \mathrm{D}$ is the duty ratio that is generated by $\mathrm{P} \& \mathrm{O}$ MPPT.

\section{MATLAB SIMULINK MODEL}

A sinusoidally varying force is given to the mass-spring damper system which generates mechanical vibrations for the mechanically coupled piezoelectric element [9-12]. According to the mechanicaly generated vibrations given to the piezo element, sinusoidally varying ac electrical output is generated which is sensed by a voltage sensor which is then passed to the interfaced electrical circuit consisting of a single phase full wave PWM rectifier which converts the sinusoidally varying ac input from piezo element into pulsating DC voltage. Here PWM rectifier is used to reduce the total harmonic distortions in the output created by the switches in the rectifier. This pulsating dc output voltage from the rectifier is then pass through a capacitive filter for reducing distortions. Further this dc voltage is given to the boost converter to increase the DC voltage level. In one system P\&O MPPT is used to generate the duty cycle for the boost converter using the current and voltage from full wave rectifier as input, and in the other system where duty cycle for the boost converter is given through pulse generator.

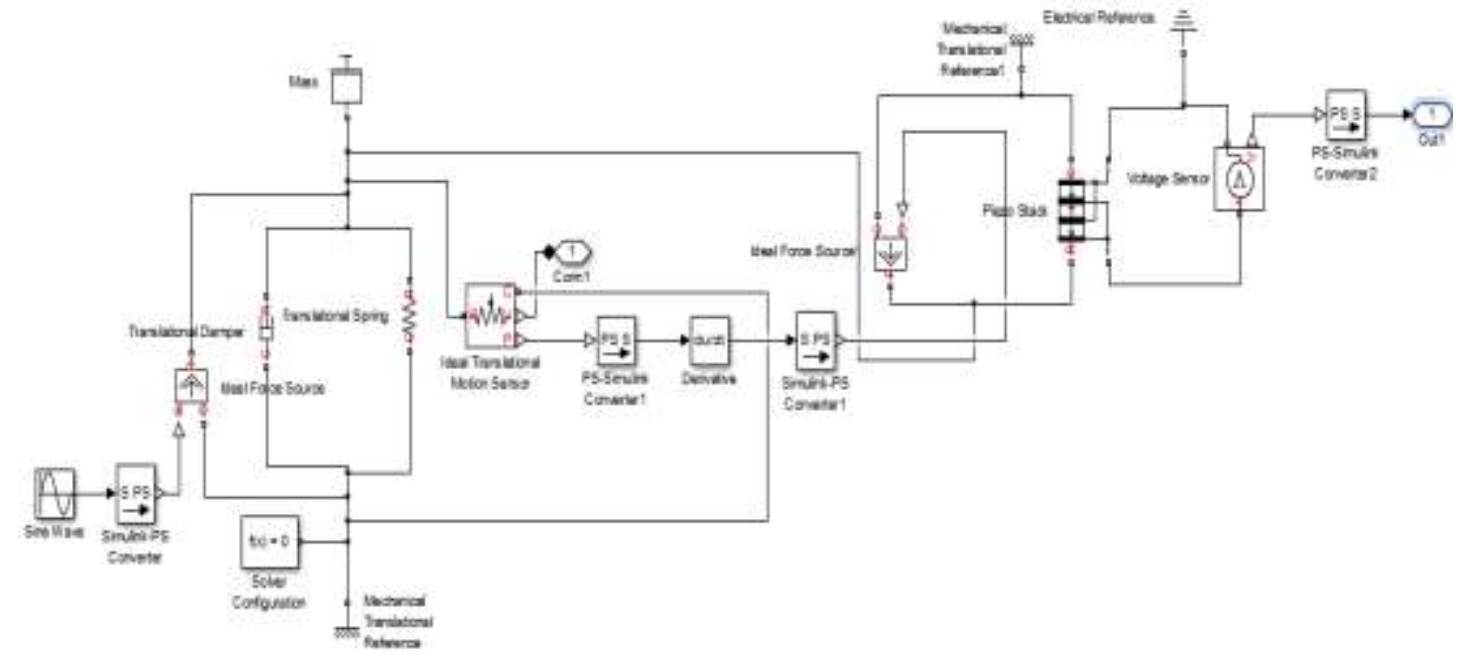

Figure 1: Simulation Model of Piezo Subsystem

Figure 1 Shows the model of Piezoelectric Subsystem consisting of the mass-spring damper system which is provided with the sinusoidal force input, the displacement caused in the spring and damper due to this force creates the vibrations for the piezo element, as per the piezoelectric effect an electrical voltage will be generated which is sinusoidally varying AC voltage.

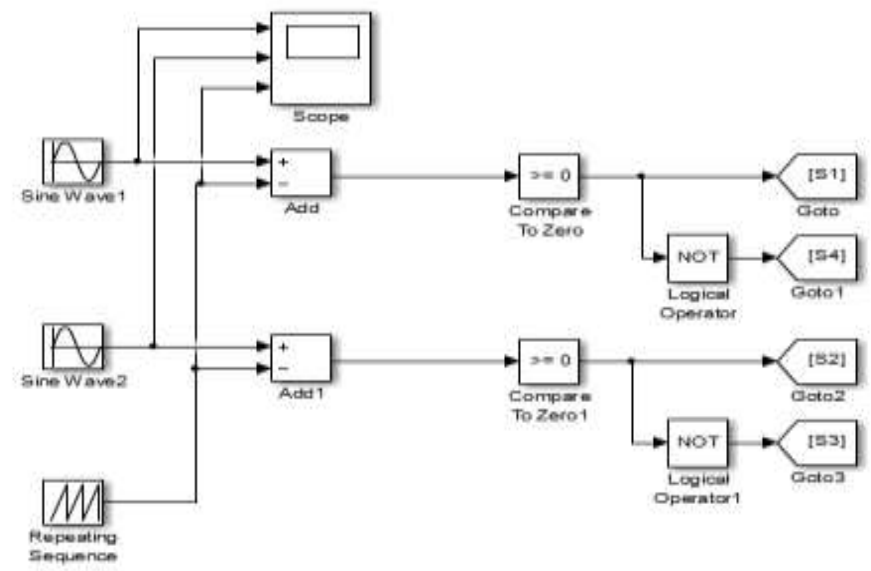

Figure 2: PWM-Rectifier Waveform Generator Modeling 
The above figure shows the PWM waveform generator for the single phase full wave rectifier with two sinusoidal inputs with one of them is 180 degrees out of phase of the other. Comparing them with the reference signal, pulses are generated where first pulse is given to the two switches and 180 degrees displaced pulse is provided to the other two switches of the rectifier.

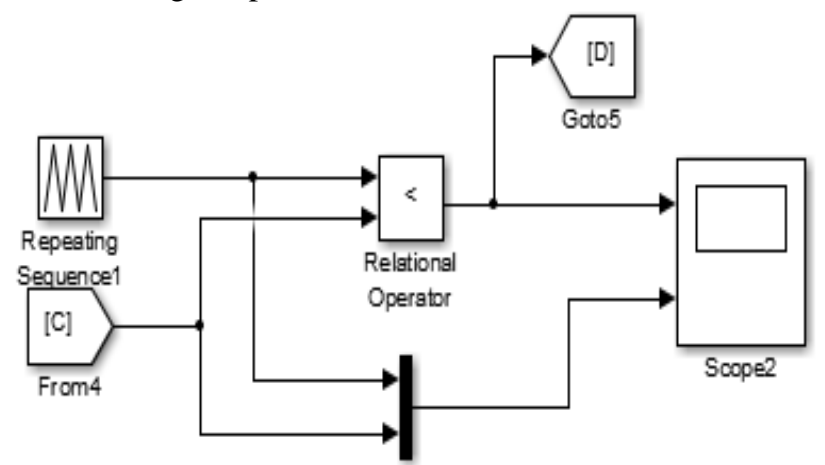

Figure 3: PWM Waveform Generator for MPPT

The output from the MPPT is compared with the reference signal to generate the pulses as the duty cycle for the switch of the boost converter.

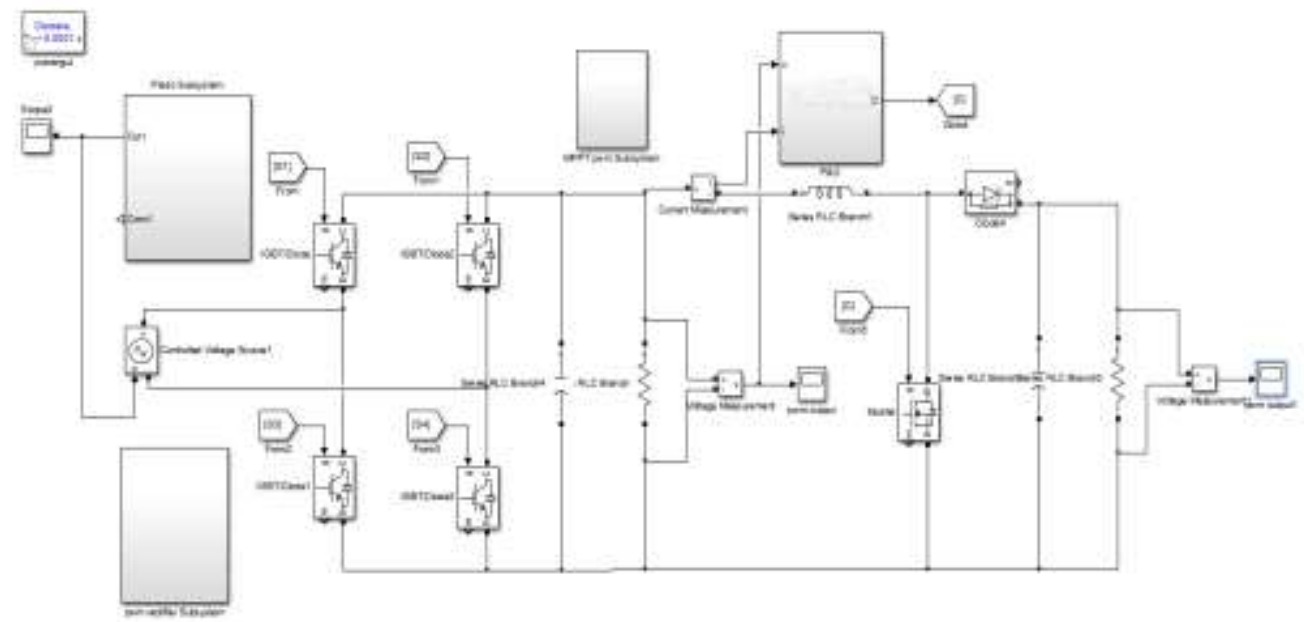

Figure 4: Simulink Model of Vibration Energy Harvester with MPPT

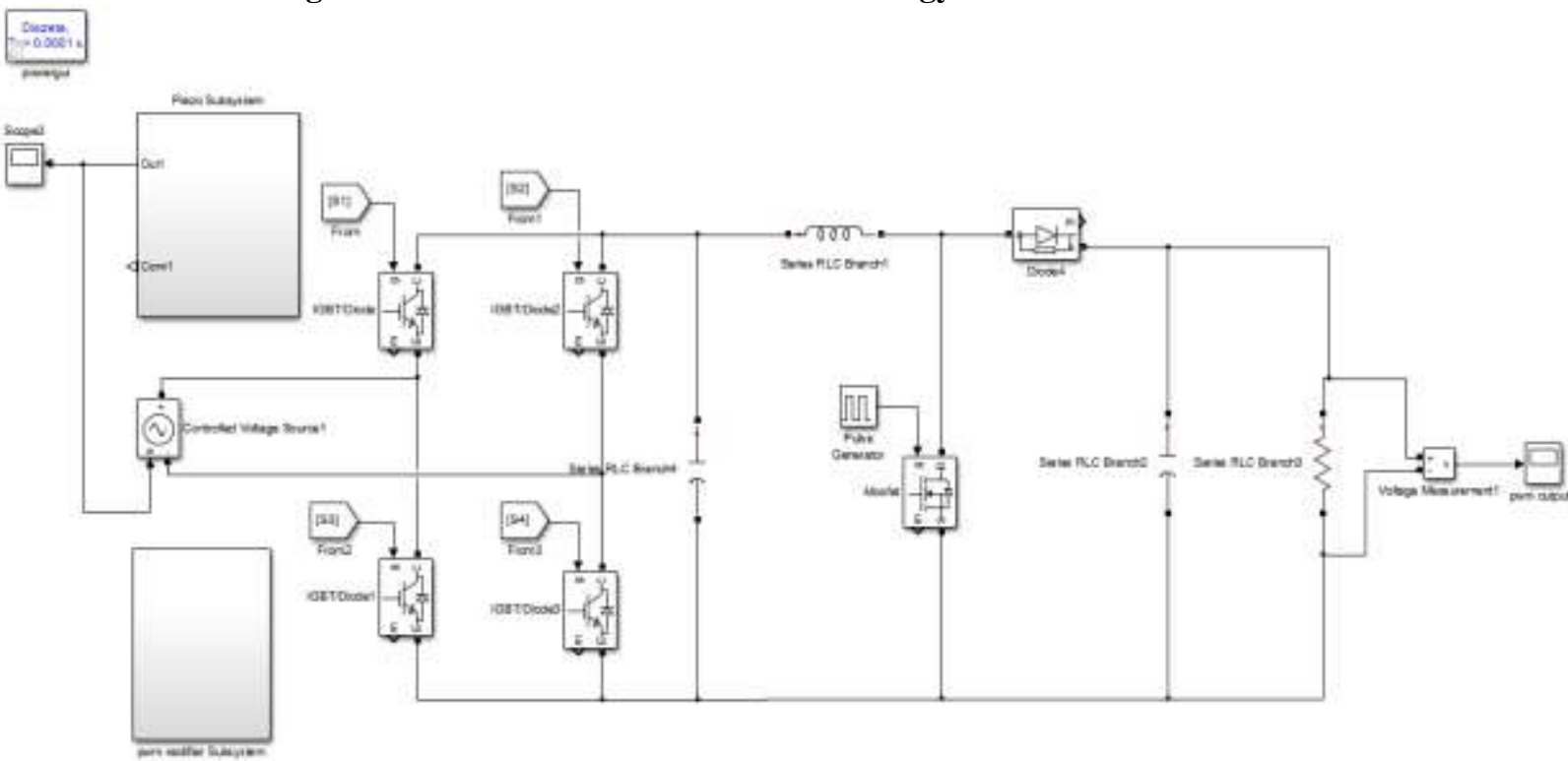

Figure 5: Simulink Model of Vibration Energy Harvester Without MPPT 


\section{ELECTROMECHANICAL MODELING AND SIMULATION OF PIEZOELECTRIC VIBRATION BASED ENERGY HARVESTER INTERFACED WITH MPPT BASED ELECTRICAL CIRCUIT USING MATLAB SIMULINK}

The output from the piezo harvester is provided to the interfaced electrical circuit. Refer to the figure 1 for piezo harvester. The low AC output voltage generated by the electromechanical piezoelectric harvester is given to the single phase full wave rectifier, where the pulse to the switches are generated by the PWM signal, refer to figure 2 . The rectifier generates the full wave pulsating dc output. In the first harvester system with MPPT, as shown in figure 4, the current and voltage output from PWM rectifier to the P\&O MPPT to generate the duty cycle using the PWM signal, refer to figure 3 , this generated duty cycle is given to the MOSFET switch of the boost converter. According to the duty cycle from MPPT and the rectifier output, a constant high DC voltage output is produced.

The other electromechanical piezoelectric energy harvester interfaced with electrical circuit without MPPT, as shown in figure 5 , the output from the piezo harvester, refer to figure 1 , the generated sinusoidal ac voltage is provided to the single phase full wave PWM rectifier, where the PWM signals are generated as shown in figure 2, the rectifier converts the AC output from piezo system into pulsating DC output. The output from the rectifier is given to the capacitive filter to reduce the distortions. The generated output from filter is forwarded to the boost converter, where the MOSFET in the converter is provided with the pulse from the pulse generator, to produce the duty cycle. As per the duty cycle and the output from the rectifier, constant dc voltage is generated by the boost converter.

\section{RESULT}

The sinusoidal force input to the electromechanical piezoelectric harvester produces the electrical voltage output which is sinusoidal ac voltage output.

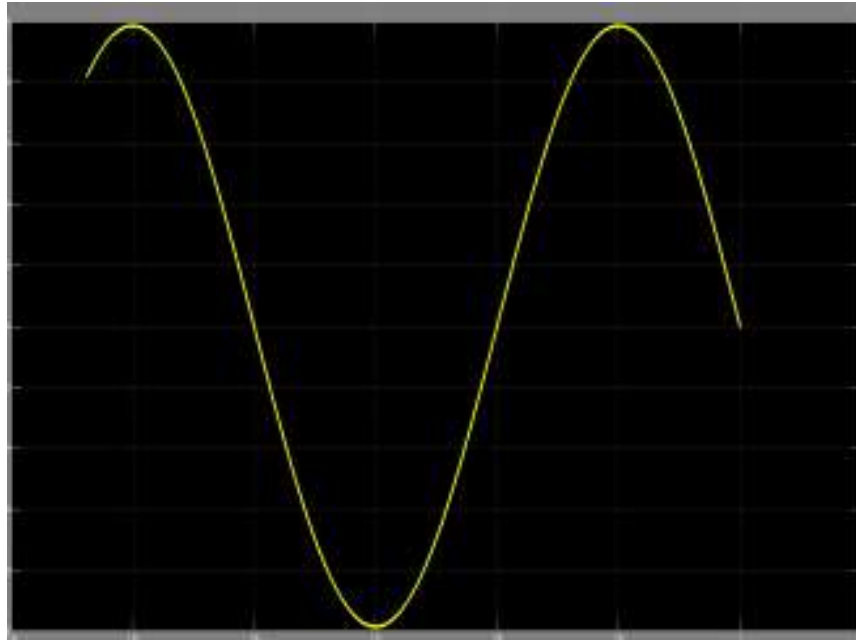

Figure 6: AC Voltage Output from Piezoelectric Element

The comparison between the Piezoelectric vibration energy harvester with MPPT and without MPPT has been drawn. The vibrational harvester system with P\&O MPPT generates high DC output which can be used for various applications, and the harvester system without MPPT generates low DC output voltage for low power applications.

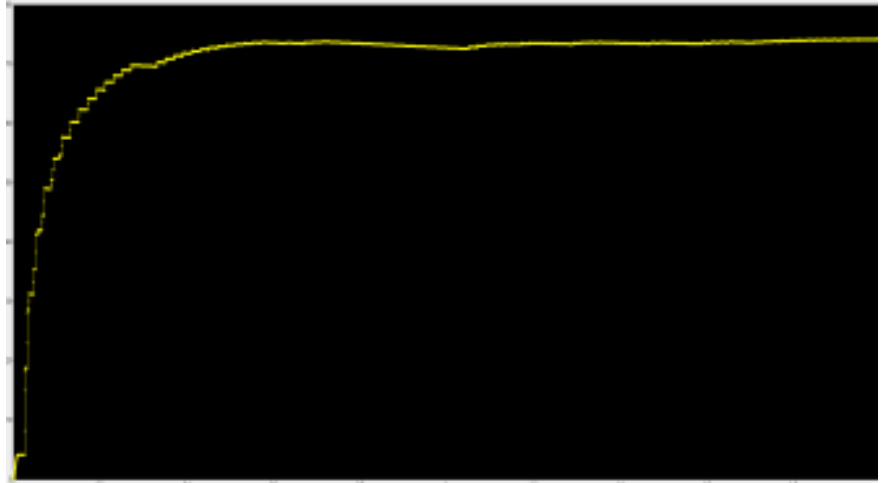

Figure 7: DC Output Voltage from Havester with MPPT

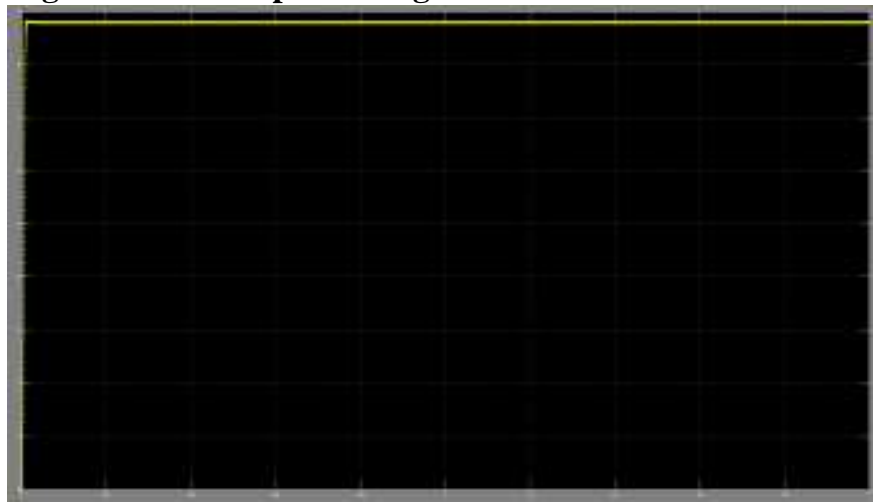

Figure 8: DC Output from Harvester Without MPPT

A comparison table has been made between the vibrational energy harvester system with and without MPPT. The following informations about output voltage, current, total harmonic distortion in the system and the ripple factor have been drawn, as shown in the table below.

\begin{tabular}{|l|l|l|}
\hline & $\begin{array}{l}\text { With } \\
\text { MPPT }\end{array}$ & $\begin{array}{l}\text { Without } \\
\text { MPPT }\end{array}$ \\
\hline Output Voltage & $75 \mathrm{~V}$ & $8.8 \mathrm{~V}$ \\
\hline Output Current & $1.5 \mathrm{~mA}$ & $0.175 \mathrm{~mA}$ \\
\hline THD (\%) & 84.94 & 84.94 \\
\hline Ripple Factor $(\%)$ & 13.33 & 113.63 \\
\hline
\end{tabular}

The piezoelectric energy harvester with interfaced single phase full wave pwm rectifier, P\&O MPPT and boost converter generates DC output voltage of $75 \mathrm{~V}$ whereas the system without $\mathrm{P} \& \mathrm{O}$ MPPT generates $8.8 \mathrm{~V}$ dc output voltage.

The output current generated by the system with MPPT is $1.5 \mathrm{~mA}$ which is a large current output as compared to the system without MPPT a low cuurent output of value $0.175 \mathrm{~mA}$ is produced.

The total harmonic distortion generated in system with MPPT and without MPPT are equal, but the ripple factor due to the converter is less in the harvester with MPPT as compered to the system without MPPT. 


\section{CONCLUSION}

In this paper a comparison has been drawn between the piezoelectric vibration energy interfaced with electrical circuit with MPPT and without MPPT. By taking the resistive load of $50 \mathrm{~K} \Omega$ it is found that the piezoelectric harvester with MPPT generates high DC electrical output voltage which makes it appropriate for the applications. The switching frequency for the switch of boost converter in the system without MPPT is $50 \mathrm{KHz}$. Although the total harmonic distortion generated by both the systems with and without MPPT are same, but the ripple factor generated by the harvester with MPPT is very less as compared to the harvester system without P\&O MPPT. It is found that the vibration energy harvester with $\mathrm{P} \& \mathrm{O} \mathrm{MPPT}$ generates more electrical output with less ripples in the output.

\section{REFERENCES}

1. Vrunda $\mathrm{R}$ Kotdawala, Vithal $\mathrm{N}$ Kamat, "Electromechanical Modeling and Simulation of Piezoelectric Energy Harvester," International Journal of Advance Engineering and Research Development, Volume 5, 2018.

2. C.B. Williams, R.B. Yates, "Analysis of a micro-electric generator for microsystems." In Sens. Actuators A: Phys. 52(1-3), 8-11 (1996)

3. Elvin, N.G. and Elvin, A.A., and Spector, M., "A SelfPowered Mechanical Strain Energy Sensor," in Smart Materials and Structures, Vol. 10, pp. 293-299. 2001.

4. Ottman, G.K., Hofmann, H., Bhatt A. C. and Lesieutre, G. A., 2002, "Adaptive Piezoelectric Energy Harvesting Circuit for Wireless, Remote Power Supply," IEEE Transactions on Power Electronics, Vol. 17, No.5, pp. 669-676.

5. Hofmann, H., Ottman, G.K. and Lesieutre, G.A.,2003, "Optimized Piezoelectric Energy Circuit Using StepDown Converter in Discontinuous Conduction Mode," IEEE Transactions on Power Electronics,Vol. 18, No.2, pp. 696703 .

6. Sodano, H.A, Park, G. and Inman, D.J., 2004b, "Estimation of Electric Charge Output for Piezoelectric Energy Harvesting," Journal of Strain, Vol. 40, pp. 4958.

7. J Ajitsaria, S Y Choe, D Shen and D J Kim, "Modeling and analysis of a bimorph piezoelectric cantilever beam for voltage generation" in Smart Mater. Struct. 16 (2007) 447-454

8. Daniel Motter; Jairo Vinícius Lavarda; Felipe Aguiar Dias; Samuelda Silva,Vibration energy harvesting using piezo electric Transducer and non-controlled rectifiers circuits, J. Braz. Soc. Mech. Sci. \& Eng. vol.34 no.spe Rio de Janeiro 2012

9. Hiroaki Takeda, Kensuke mihara, Tomohiro yoshimura, "Effect of Material Constants on Power Output in Piezoelectric Vibration-Based Generators", IEEE Transactions On Ultrasonics, Ferroelectrics, And Frequency Control, vol. 58, no. 9, september 2011,1852

10. Ahmed Telba, IAENG, Wahied G. Ali, "Modeling and Simulation of Piezoelectric Energy Harvesting ",Proceedings of the World Congress on Engineering 2012 Vol II WCE 2012, July 4 - 6, 2012, London, U.K.

11.S Boisseau1, G Despesse1, T Ricart1, E Defay1 and A Sylvestre2Cantilever-based electret energy harvesters , 2011 Smart Mater. Struct. 20105013

12. Dhananjay Kumar, Pradyumn Chaturvedi and Nupur Jejurikar, “ Piezoelectric Energy Harvester Design and
Power Conditioning”,2014 IEEE Students Conference on Electrical, Electronics and Computer Science

13. S Priya, Shashank, Inman, Daniel J. „Energy Harvesting Technologiese A Book by (Eds.),2009,Springer.

14. Huidong Li, Chuan Tian, and Z. Daniel Deng, “ Energy harvesting from low frequency applications using piezoelectric materials" Applied Physics Reviews 1, 041301 (2014)

15.Guthi Prakash1 , Dr.Pradeepa.S2, "Modelling and Simulation of Piezoelectric Energy Harvester for Electronic Devices", International Journal for Research in Applied Science \& Engineering Technology (IJRASET), Volume 5 Issue X1, November 2017

16. Manual of Measuring Properties of Piezoelectric Ceramics, Sparkler Ceramics Pvt. Ltd. Bhosari, Pune, India.

17. Piezo Film Sensors Technical Manual, Measurement Specialties, Inc. Norristown, PA 